\title{
RANCANGAN PERANGKAT KENDALI IRIGASI TETES MENGGUNAKAN SISTEM MINIMUM KOMPUTER
}

\author{
Ahmad Rofiq Hakim \\ Program Studi Teknik Komputer \\ Politeknik Negeri Samarinda \\ E-mail: rofiq_93@yahoo.com ${ }^{1}$
}

\begin{abstract}
Abstrak - Penelitian bertujuan untuk merancang perangkat untuk mengendalikan irigasi tetes untuk tanaman yang bekerja secara otomatis menggunakan sistem minimum komputer. Penelitian ini bermanfaat untuk membantu para petani, masyarakat, maupun instansi - instansi terkait di bidang agrikultur dalam melakukan proses irigasi pada tanaman dan memantau kondisi tanaman terkait irigasi secara langsung.

Penelitian ini mengikuti tahapan penegmbangan sistem waterfall model yaitu analisis dan desain yang mencakup perangkat lunak dan perangkat keras.

Adapun hasil akhir dari penelitian ini yakni berupa rancangan perangkat untuk mengendalikan irigasi tetes menggunakan sistem minimum komputer yang bekerja secara otomatis pada proses penanaman berbagai tanaman, terutama tanaman yang dikembangkan oleh para petani seperti sayursayuran.
\end{abstract}

Kata Kunci: kendali, irigasi tetes, tanaman, sistem minimum computer

\section{PENDAHULUAN}

Indonesia merupakan daerah yang memiliki dua musim, yaitu musim hujan dan musim kemarau. Proses terjadinya musim hujan dan musim kemarau dipengaruhi oleh beberapa hal, sehingga pemakaian air tergantung pada jumlah dan kejadian hujan. Curah hujan pada umumnya cukup tapi jarang sekali secara tepat dan sesuai dengan kebutuhan untuk pertumbuhan tanaman. Oleh karena itu perlu dikembangkan sistem pengairan yang baik, agar ketersediaan air dapat mencukupi selama proses pertumbuhan tanaman berlangsung, salah satunya yaitu metode irigasi.

Salah satu jenis metode irigasi yang dapat dipergunakan adalah irigasi tetes. Metode irigasi tetes merupakan teknologi irigasi yang bertujuan memanfaatkan ketersedian air yang sangat terbatas secara efisien dan meningkatkan nilai pendaya-gunaan air. Pada sistem irigasi tetes, air didistribusikan dari tangki penampung yang ditem-patkan pada posisi yang lebih tinggi dari lahan pertanian ke setiap daerah perakaran tanaman melalui selang irigasi. Pada sistem irigasi tetes diperlukan pengontrolan untuk mencegah tejadinya kekurangan dan kelebihan pemberian air. Jika tidak dilakukan pengontrolan, maka proses pengairan akan menjadi tidak efisien.

Dari latar belakang in, diperlukan suatu penelitian yang akan memberikan suatu alternatif sistem irigasi pertanian guna membantu proses pertumbuhann tanaman yaitu pengendali irigasi tetes menggunakan sistem minimum komputer.

\section{RUANG LINGKUP PENELITIAN}

Dalam penelitian ini permasalahan mencakup :

1) Irigasi di lakukan pada media tanam berbasis tanah.
2) Dilakukan pada tanaman berskala kecil yaitu tanaman rumah tangga, tanaman pot, atau proses pembibitan tanaman (semai).

Adapun tujuan dari penelitian ini adalah sebagai berikut :

1) Menghasilkan desain perangkat kendali irigasi tetes menggunakan sistem minimum kompter

2) Membantu dalam mengatur dan mengawasi tanaman untuk menjaga kondisi tanaman agar tercukupi kebutuhan airnya.

3) Mengatur distribusi air sesuai dengan kebutuhan dan kondisi tanah di lingkungan.

\section{ANALISIS DAN PERANCANGAN}

\subsection{Analisis}

Untuk membangun sebuah alat irigasi otomatis pada tanaman dibutuhkan perangkat keras dan perangkat lunak.

Perangkat keras dibutuhkan untuk membangun perangkat fisik dari kendali irigasi tetes, dibutuhkan beberapa komponen yaitu :

1. Sistem Minimum Komputer sebagai komponen utama yang akan digunakan untuk mengendalikan alat secara keseluruhan

2. Sensor untuk membaca kondisi-kondisi yang terkait dengan aktifitas pengaliran air seperti kelembaban dan suhu

3. Pompa air untuk memompa air sehingga dapat mengalir untuk memberian irigasi tetes

4. Katup atau Kran air untuk buka tutup aliran air dalam proses irigasi tetes

5. Sumber tegangan agar perangkat dapat 
bekerja

Adapun perangkat lunak dibutuhkan untuk membangun logika-logika kendali yang akan tersimpan di dalam memori sistem minimum komputer guna mengendalikan perangkat kerasi kendali irigasi tetes, dibutuhkan software yang terkait dengan sistem minimum komputer seperti bahasa $\mathrm{C}$ atau Asembler

Perangkat kendali dirancang untuk bekerja yaitu :

1. Sesor membaca kondisi dilingkungan sekitar yaitu suhu dan kelembaban tanah

2. Setiap pembacaan pada sensor akan dikirimkan ke sistem minimum untuk dianalisis dan dibandingkan dengan ukuran kelembaban tanah dan suhu untuk diputuskan apakah perlu mengalirkan air ke area penanaman

3. Jika dipustuskan mengalirkan air ke area penanaman, maka sistem minimum akan mengaktifkan pompa air dan membuka katub/kran air agar air mengalir ke irigasi tetes. Pada saat ini sensor tetap membaca kondisi suhu dan kelembaban tanah dan terus mengirim data ke sistem minimum komputer

4. Jika hasil pembacaan sensor yang terus menerus dikirimkan ke sistem minimum komputer memutuskan bahwa kelembaban tanah dan suhu sudah sesuai atau melebihin standar, maka proses mengalirkan air ke area penanaman dihentikan, pompa dimatikan dan katub/kran iar ditutup.

\subsection{Perancangan}

\subsubsection{Perancangan Perangkat Keras}

Adapun tahap - tahap perancangan perangkat keras sebagai berikut :

\section{1) Desain Blok Diagram}

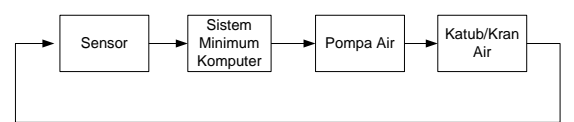

Gambar 1. Desain blok diagram perangkat kendali irigasi tetes

\section{2) Sensor}

\section{a. Sensor Suhu}

Sensor Suhu atau Temperature Sensors adalah suatu komponen yang dapat mengubah besaran panas menjadi besaran listrik sehingga dapat mendeteksi gejala perubahan suhu pada obyek tertentu. Sensor suhu melakukan pengukuran terhadap jumlah energi panas/dingin yang dihasilkan oleh suatu obyek sehingga memungkinkan kita untuk mengetahui atau mendeteksi gejala perubahanperubahan suhu tersebut dalam bentuk output Analog maupun Digital. Sensor Suhu juga merupakan dari keluarga Transduser.

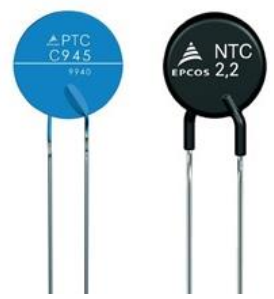

Gambar 2. Sensor Suhu NTC dan PTC (thermistor)

\section{b. Sensor Kelembaban}

Kelembaban adalah merupakan nilai kadar air atau nilai endapan air pada udara maupun benda. Kelembaban mendeteksi perubahan parameter fisik seperti tahanan atau output voltage yang berhubungan dengan perubahan kadar air. [7]

Sensor kelembaban yang dapat digunakan salah satunya adalah Soil moisture sensor adalah sensor beresistensi listrik yang dapat mendeteksi kelembaban tanah. Sensor ini sangat sederhana, tetapi sangat ideal untuk memantau kelembaban taman kota, kebun, lahan, atau tingkat air pada tanaman pekarangan rumah.

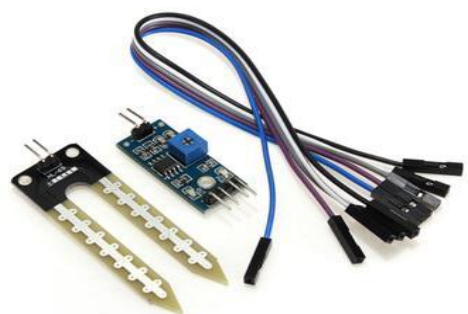

Gambar 3. Soil moisture sensor

Sensor ini terdiri dari dua elektroda untuk di tancapkan di tanah kemudian membaca resistensinya untuk mendapatkan tingkat kelembaban di sekitarnya. Semakin banyak air membuat tanah lebih mudah menghantarkan listrik (resistansi kecil), sedangkan tanah yang kering sangat sulit menghantarkan listrik (resistansi besar)[2].

\section{3) Sistem Minimum Komputer}

Sistem minimum komputer adalah suatu perangkat yang memuat unit-unit atau bagianbagian yang memiliki fungsi-fungsi kerja dari sebuah komputer secara terbatas sesuai dengan kebutuhan, diantaranya yaitu unit input, output, memori, dan pusat pemroses data (CPU)

Salah satu sistem minimum komputer yang dapat digunakan adalah Arduino UNO, yaitu board mikrokontroler berbasis ATmega328 
(datasheet). Memiliki 14 pin input dari output digital dimana 6 pin input tersebut dapat digunakan sebagai output PWM dan 6 pin input analog, $16 \mathrm{MHz}$ osilator kristal, koneksi USB, jack power, ICSP header, dan tombol reset. Untuk mendukung mikrokontroler agar dapat digunakan, cukup hanya menghubungkan

Board Arduino Uno ke komputer dengan menggunakan kabel USB atau listrik dengan AC yang-ke adaptor-DC atau baterai untuk menjalankannya.Uno berbeda dengan semua board sebelumnya dalam hal koneksi USB-toserial yaitu menggunakan fitur Atmega8U2 yang diprogram sebagai konverter USB-toserial berbeda dengan board sebelumnya yang menggunakan chip FTDI driver USB-to-serial.

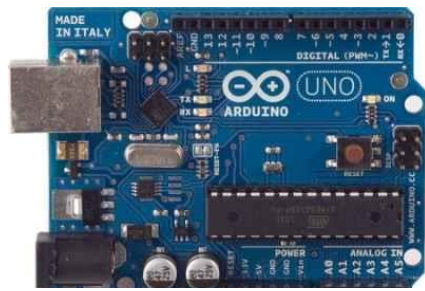

Gambar 4. Arduino UNO

\section{4) Katub Air atau Kran Solenoid Valve}

Solenoid valve merupakan katup yang dikendalikan dengan arus listrik baik AC maupun DC melalui kumparan / selenoida. Solenoid valve ini merupakan elemen kontrol yang paling sering digunakan dalam sistem fluida. Seperti pada sistem pneumatik, sistem hidrolik ataupun pada sistem kontrol mesin yang membutuhkan elemen kontrol otomatis. Contohnya pada sistem pneumatik, solenoid valve bertugas untuk mengontrol saluran udara yang bertekanan menuju aktuator pneumatic (cylinder).

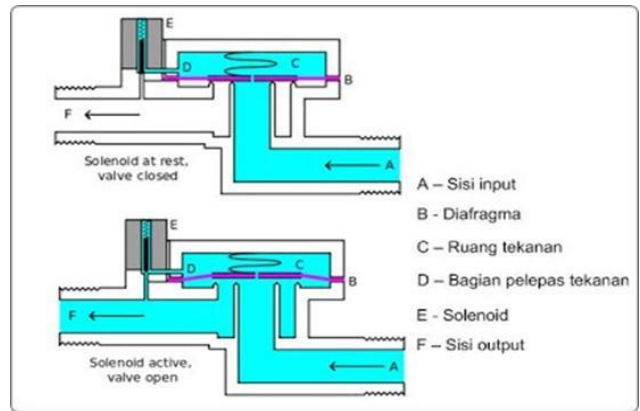

Gambar 5. Prinsip kerja solenoid valve

\section{5) Desain Wiring Diagram}

Wiring diagram yang menghubungkan antar komponen perangkat keras dalam rancangan Perangkat Kendali Irigasi tetes ini dapat dilihat pada gambar 6

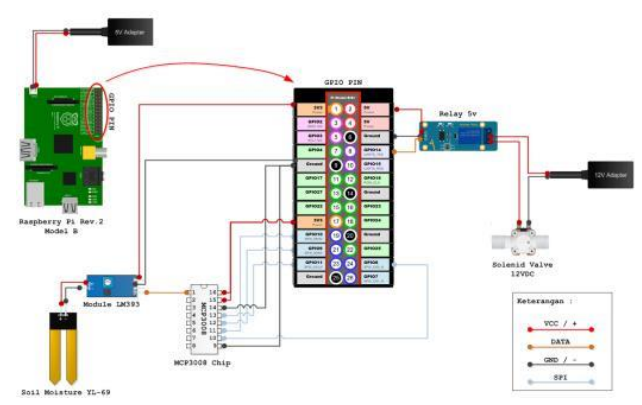

Gambar 6. Rancangan Wiring Diagram Perangkat Keras

\subsubsection{Perancangan Perangkat Lunak Desain Flowchart}

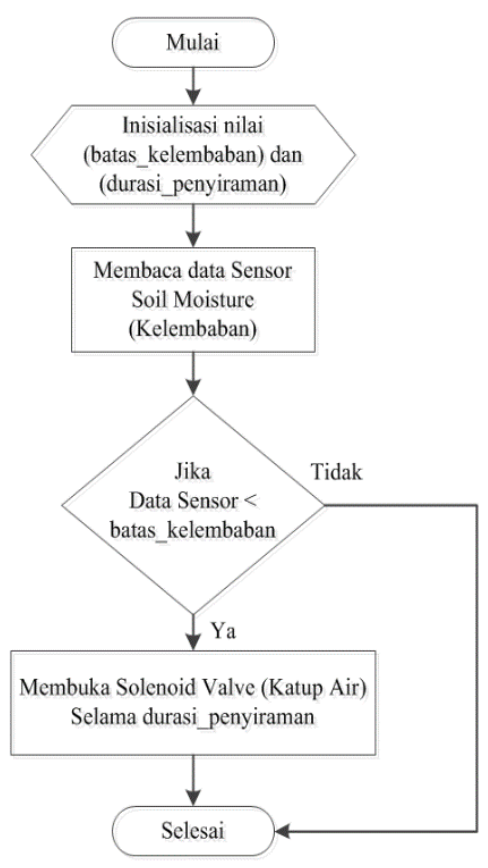

Gambar 6. Desain Flowchart Perangkat Lunak

Pada alat irigasi otomatis tanaman ini proses yang pertama kali ialah sistem melakukan inisialisasi dengan membaca nilai batas kelembaban dan durasi penyiraman yang sudah di tentukan kemudian sensor soil moisture mendeteksi objek berupa kadar air yang ada di dalam tanah lalu data hasil dari deteksi tersebut akan diproses oleh sistem minimum, jika hasil data sensor kurang dari nilai batas kelembaban maka akan membuka katub air selama durasi penyiraman

\section{KESIMPULAN}

1) Perancangan perangkat kendali irigasi tetes menggunakan sistem minimum komputer menggunakan beberapa komponen perangkat keras yaitu sensor suhu dan kelembaban, sistem minimum komputer, 
Hakim, Rancangan Perangkat Kendali Irigasi Tetes Menggunakan Sistem Minimum Komputer

pompa air dan katub /kran air.

2) Untuk dapat berfungsi maka pada Perangkat kendali dibenamkan perangkat lunak yang berisi logika-logika kendali sesuai kebutuhan yaitu pembacaan input dari sensor dan pengedalian pompa dan katub/kran air

\section{SARAN}

Untuk dapat diimplementasikan baik perangkat kerasa dan perangkat lunak diperlukan penyesuaian yang mungkin perlu penambahan komponen dan algoritma sesuai dengan kondisi di lapangan

\section{REFERENSI}

[1] Ariska, N. 2015. Partisipasi Petani dalam Pemeliharaan Irigasi dan Kontribusinya Terhadap Produksi Padi. Fakultas Pertanian, Makassar: Universitas Hasanuddin.

[2] Njoroge, K, P. 2008. Microcontroller-Based Irrigation System, Fakultas Elektronika dan Teknik Informatika, Nairobi: Universitas Nairobi.

[3] Popi. 2015. Mempelajari Karakteristik Irigasi Tetes Pada Tanaman Durian (Durio zibethinus L). Fakultas Pertanian, Makassar: Universitas
Hasanuddin.

[4] Proboyekti, U. 2009. Flowchart, (Online) (http://lecturer.ukdw.ac.id/othie/flowchart.pdf), di akses 23 Mei 2016.

[5] Roger, S. Pressman, Ph.D. , 2012, Rekayasa Perangkat Lunak (Pendekatan Praktisi) Edisi 7 : Buku 1 “, Yogyakarta: Andi.

[6] Rosyady, Mardani, Implementasi Irigasi Otomatis Pada Tanaman Menggunakan Raspberry Pi, STMIK Widya Cipta Dharma, Samarinda

[7] Rozikin, C. 2013. Akuisisi Data Irigasi Menggunakan Multiple Sensor Berbasis Wireless Sensor Network, Tesis. Bogor: Institut Pertanian Bogor.

[8] Suprianto. 2015. Pengertian Dan Prinsip Kerja Solenoid valve, (Online), http://blog.unnes.ac.id/anto-supri-/pengertian dan prinsip-kerja-solenoid-valve/), diakses 5 Mei 2016.

[9] Suryantini, Fitria, dkk., 2019, Implementasi Sistem Kontrol Irigasi Tetes Menggunakan Konsep IoT Berbasis Logika Fuzzy Takagi-Sugeno, JTERA (Jurnal Teknologi Rekayasa), Vol. 4, No. 1, Sukabumi

[10]Udiana, I,M. 2014. Perencanaan Sistem Irigasi Tetes (Drip Irrigation) di Desa Besmarak Kabupaten Kupang. Jurusan Teknik Sipil, Kupang: Universitas Nusa Cenda 
JUST TI, Volume 11 Nomor 1, Januari 2019: 52-55 